\title{
Assessing for Rising Visuospatial Ability of School Leavers
}

\author{
E. A. Cocodia ${ }^{1}$ \\ ${ }^{1}$ University of Notre Dame Australia, Sydney, NSW Australia \\ Correspondence: E. A. Cocodia, University of Notre Dame Australia, Sydney, NSW Australia. E-mail: \\ Ebinepre.cocodia@nd.edu.au \\ Received: March 31, 2015 \\ Accepted: April 3, 2015 \\ Online Published: May 29, 2015 \\ doi:10.5539/ijps.v7n2p113 \\ URL: http://dx.doi.org/10.5539/ijps.v7n2p113
}

\begin{abstract}
This paper investigated increasing visuospatial ability in three countries. Drawing on the Flynn Effect some researchers (Greenfield, 1998; Neisser, 1997) hypothesized that visuospatial ability may be increasing. I explored rising visuospatial abilities amongst school leavers in the UK, Australia and Nigeria. In one study Cocodia et al. (2003) found that exposure to new technology may be impacting on ability to carry out tasks that require high levels of visuospatial ability more efficiently. Results suggest that increasing visuospatial ability may be occurring due to a more visual environment and more access to multimedia. The core component of the present research paper was to investigate whether visuospatial ability is indeed rising as it is a feature of the human intelligence framework (Halpern \& LaMay, 2000; Alias, Gray, \& Black, 2001). Data analysis of examination results in specific subjects indicated that visuospatial abilities are rising. It was hypothesized that visuospatial ability is rising in industrialized nations due to more access to multimedia, and cognitive manipulation task in general.
\end{abstract}

Keywords: Australia, Nigeria, United Kingdom, school leavers, visuospatial ability

\section{Introduction}

Visuospatial ability is a subset of the human intelligence structures. Lohman (2000, p. 285) describes visuospatial ability as an aspect of spatial ability which assists to mentally "generate, retain, retrieve, and transform well structured visual images". It is also defined as: “...the ability to manipulate and rotate two- and three- dimensional pictorially presented stimulus objects” (McGee, 1982, p. 893). Significantly, Flynn (1984, 1987) found that scores on those IQ tests which rely heavily on visuospatial ability, were higher than verbal ability test. Visuospatial strategies may also be employed to solve mathematical problems on tests which require advanced mathematical reasoning (Thomas \& Higbee, 1999; Halpern \& LaMay, 2000; McGee, 1982; Wilson \& Swanson, 2001). Halpern and LaMay (2000) point out that visuospatial ability consists of subsets of abilities and is not a unitary construct. There are 5 abilities within the visuospatial framework (see Table 1).

Table 1. Five abilities within the visuospatial framework (Adapted from Halpern \& LaMay, 2000, pp. 235-236).

\begin{tabular}{|c|c|}
\hline Abilities & Description \\
\hline Spatial perception & $\begin{array}{l}\text { Requires a participant to locate the horizontal or vertical } \\
\text { in a stationary display while ignoring distracting } \\
\text { information; }\end{array}$ \\
\hline Mental rotation & $\begin{array}{l}\text { Involves the ability to imagine how objects may appear } \\
\text { when they are rotated in two- or three dimensional } \\
\text { spaces; }\end{array}$ \\
\hline Spatial Visualisation & $\begin{array}{l}\text { Refers to the complex analytic multistep processing of } \\
\text { spatial information }\end{array}$ \\
\hline Spatiotemporal ability & $\begin{array}{l}\text { Involves judgements and responses to dynamic (i.e. } \\
\text { moving) visual displays. }\end{array}$ \\
\hline Generation and maintenance of a spatial image & $\begin{array}{l}\text { Require one to generate an image form long or short term } \\
\text { memory, using the information to perform a specific } \\
\text { cognitive task }\end{array}$ \\
\hline
\end{tabular}




\section{Technological Advancement and Rising Visuospatial Abilities}

Exposure to technological and visual environments in modern society is described as part of the cultural development of a society (Neisser, 1997). According to Neisser increased access to information and communication technology has been suggested as a possible causal factor for rising IQ test scores. Others have also linked the perceived rise to general technological advancement (Teasdale \& Owen, 2000; Greenfield, 1998). Television, film, visual media, and internet access are just some of the changes which have impacted on the human environment since the 1920s. More access to information means people have access to more knowledge. Knowledge is described as information which is acquired and accumulated (Gilhooly, 1994). Through more information mediums like these we can acquire a large pool of knowledge as well as other skills and concepts. Depending on how highly structured one's knowledge base is, the information we acquire can assist in IQ tests. This is especially pertinent when performance involves problem solving tasks (Ceci, 1991). For example, if a test item requires the examinee to mentally rotate objects on a picture test, playing computer games have been found to enhance this skill (Greenfield, 1998). If an individual's reservoir of knowledge in a given domain is well structured, the relevant cognitive processes (e.g. encoding, retrieval, inference) that access this knowledge when solving new problems will be utilized efficiently (for a full account of how our cognitive architecture and processes influence knowledge acquisition see Sweller, 1999).

Increasing technical and visual environments are also evident in formal education settings. Children now have more access to more technology and computers for a variety of classroom activities including mathematics and science. Schools have integrated computer technology is classroom practice (Ogbu, 1994). Theories have emerged suggesting that continuous contact with these technologies may be impacting IQ test scores. Curtis and Lawson (2002) list the benefits of computer games and new computer applications as inclusive in the development of language, problem solving and social interaction. One may use domain specific knowledge like inferring, monitoring or deductive reasoning to solve such problems (Sherwood, 1988; Henderson-Lancett \& Boesen, 1986). A person's store of knowledge helps to comprehend a situation, select moves which in turn affect outcomes. These skills obviously become very useful when taking IQ tests. Greenfield (1998) proposes that students spend long periods playing computer video games which may help develop visuospatial skills which are useful for completing items on nonverbal IQ tests. These skills are essential for completing tasks on nonverbal IQ measures such as various block design tests. Specifically, object Assembly Subtests of the Wechsler Scales and the Raven Matrices are examples of block tests. Greenfield points out that some video and computer games require the player to position objects on certain parts of the screen. More recent development of computer application may further enhance these skills. Hence, the player has to mentally manipulate each object before physically making his/her next move. The argument is that such tasks exploit skills like visuospatial representation and iconic imagery. Long periods of playing computer games requiring mental manipulations of spatial imagery may stimulate internal forms of representation (Greenfield, 1998; Okagaki \& Frensch, 1994). Many of these computer games also require one to solve puzzles or assemble two or three dimensional images on the screen. Assembling images may require mental rotations and manipulations that are also required by mental paper folding tests (e.g. Stanford-Binet Mental Paper folding Test and the Wechsler Scales for Children). Greenfield (1998) pointed out that film, television and video are more iconic in nature, that is, they require iconic rather than symbolic imagery over word as do nonverbal IQ tests. In addition, film and video assist in visual perspective-taking skills. These include computer software which require visual perspective skills. The author proposes that although we engage in mental manipulations using external apparatus, this should transcend to internal forms of representation (i.e. schemas) which would manifest when taking tests.

Studies have found that television and films may also influence verbal ability of children (Rice et al., 1990; Rice \& Woodsmall, 1988; Salomon, 1977; Stein \& Friedrich, 1975). This implies that if basic vocabulary is improving, verbal IQ score should be rising (Greenfield, 1998; Williams, 1998). In a longitudinal study, Rice et al (1990) studied children over a period of two years to investigate the effect of television on vocabulary development. The sample consisted of over 300 children aged between 3-7 years. Rice et al. reported that watching Sesame Street (an educational programme) did contribute to increases in vocabulary of preschoolers. Howver, it is not clear whether IQ scores also increased. Rice et al. noted that increases in vocabulary occurred regardless of environmental and social factors such as family size, parent education, parent attitude, presence of sibling or any other factors. This significant finding may have been influenced by the content and presentation of Sesame Street. Firstly, the program is well suited for the age group sampled. Secondly, language and performance of actors have also been developed to appeal to young children. However, the study does suggest that watching television for long periods may have an impact on basic vocabulary skills which may influence performance on verbal IQ tests. 


\section{Methodology}

\subsection{The Sample}

Data was collected from national examination bodies in Australia, United Kingdom (U.K.) and Nigeria. Australia and the U.K. were selected as they are highly industrialized, while Nigeria was included because it is a developing country. Performance on subjects which require high levels of visuospatial ability was sought. Subjects such as technical drawing and art were selected as sketching and drawing require high levels of visuospatial ability (Alias, Black, \& Gray, 2002). Mathematics was also selected for the same reason. Organisations responsible for administering school leaving examinations in each country were contacted directly. The following sections provide relevant details about the method employed in obtaining and analysing the data sample. It also includes information about the national examination framework of each of the countries included in the study.

\subsubsection{Australia}

In New South Wales Australia, the school leaving examination is called High School Certificate Examination (HSC). Students who have successfully completed years 11 and 12 of senior secondary school in Australia are eligible to sit for this examination. Completion of year 12 is not compulsory in New South Wales. Students have the option of pursuing various pathways at the end of year 10 which include vocational studies, a traineeship or an apprenticeship. The Board of Studies, New South Wales is the body responsible for conducting the examination. They are also responsible for school curriculum development across all levels of primary and high school education in New South Wales.

\subsubsection{United Kingdom}

In the U.K. the Department For Education and Skills (DFES) in collaboration with other bodies administer the school leaving examinations. The Qualification and Curriculum Authority (QCA) ensures that standards are maintained. The United Kingdom includes England, Scotland, Wales and Northern Ireland. However, England, Wales and Northern Ireland share a similar qualifications framework while Scotland has a separate framework (The Scottish Certificate of Education) which differs from that of the other three regions. Public examinations and qualifications include the General Certificate of Secondary Education (GCSE) and the General Certificate of Education Advanced level (GCE A level). The GCSE examinations are taken by 15 to 16 year olds after completing 5 years of secondary school. The GCE A level is usually taken by 18 years and over. The GCE A level is equivalent to Australia's HSC and was included in this phase of the study. The Qualifications and Curriculum Authority (QCA) is the body responsible for quality control.

\subsubsection{Nigeria}

The West African Examination Council (WAEC) conducts four main categories of examinations in the sub region of West Africa. These categories are: National Examinations, International Examinations, Examinations conducted in collaboration with other Examining Bodies, and Examinations Conducted on behalf of other Examining Bodies. Since its inception in 1952 examinations conducted by the council includes the School Certificate/General Certificate of Education at both the Ordinary and Advanced levels for member countries. Current member countries include: Liberia, Nigeria, Ghana, Sierra Leone, The Gambia and Guinea. Membership is not automatic instead it remains optional. As such, each country joined the council on separate occasions. School leavers' examination performance in Nigeria was examined as the country has been a member of the council since its commencement. All states and regions in Nigeria take the national school leaving certificate examinations. Historically the GCE Ordinary and Advanced levels were the national examinations taken in Nigeria until 1988. This later changed to the Senior Secondary School Certificate Examinations (SSCE) and the West African Secondary School Certificate Examinations (WASSCE). The core difference between the previous and current school leaving examinations is that the SSCE and WASSCE are taken after 6 years of secondary school education usually at the age of 17 years and above. While the GCE "O" and "A" levels have some similarities with that of the United Kingdom examination system. The Advanced level examination was for those aged 18 and above, while the Ordinary level was for ages 15 or 16 years. These two examinations were changed to a compulsory 6-3-3-4 system of education. This includes 3 years in junior secondary school and three years in senior secondary school with the option of pursuing vocational and technical studies after junior secondary school. However the content of the old and new education system remain comparable.

\subsection{Procedure}

Data collection and analysis entailed liaising with research and measurement unit or department of the examination bodies in all three countries. The research unit assisted in sorting through archives and selecting relevant data for this study. Subjects chosen include Technical Drawing/Design and Technology, Mathematics and Art. The criteria for 
data selection included: a) subjects chosen must be a common paper that has been on offer for up to ten years, b) the subjects chosen should involve high levels of visuospatial ability to complete tasks, c) furthermore in order to make meaningful comparisons over time the data had to be made consistent so it could be analysed. Therefore only passes and above in each subject were included in the analysis. The actual number of candidates who achieved passes of up to $50 \%$ (or its equivalent) and above was included. The total number of students with passes was then changed to percentages. The period of study was between 1978 and present. Due to the large volume of data, there was a need to select five years for which data was consistently available in all three countries. Hence, years 1, 2, 3, 4, and 5 are represented in the sections below across all three countries

\subsection{Results and Discussion}

The mean and standard deviations (in percentage) of passes in all three subjects are shown in

Table 2. The data was analysed using an $F$ test to test the statistical significance of the differences among the obtained means of subjects in all three countries (

Table 1). The statistical analysis was conducted at the 0.05 level of significance with the critical value of $F$ being 3.88 . The number of students who achieved passes in each subject is shown in Table 3, Table 4 and Table 5.

Table 2. Means and standard deviations of passes (in percentages) and $F$ test statistics

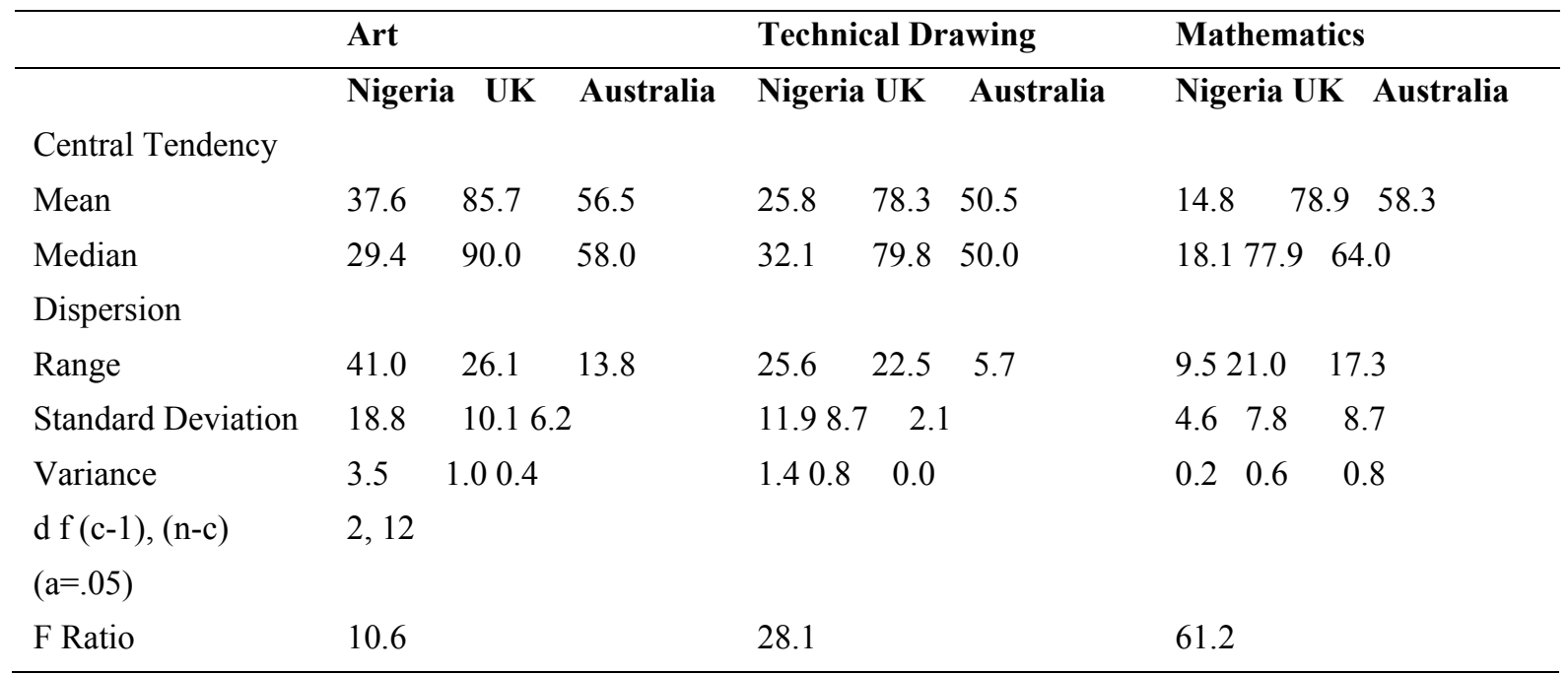

Tabled value for $F(2,12)=3.88, P<.05$

Table 3 shows the percentage and actual numbers of school leavers who achieved passes in technical drawing in all three countries. As seen in Figure 1 (also Figure 2) when compared to performance in year 1, the number of students with passes in technical drawing (TD) in each country in year 5 increased significantly. In Australia, 48 percent of school leavers passed TD in year 1 while 54 percent passed in year 5. A total of 66 percent of U.K. school leavers passed in year 1 and 88 percent passed in year 5. Performance in Nigeria also increased from 32 percent in year 1 to 38 percent in year 5. Increasing performance of school leavers in technical drawing is significant $F(2,12)=10.6$, $p<0.05$ suggesting that visuospatial ability is rising.

Table 3. School leavers achieving passes in technical drawing

\begin{tabular}{lllllll}
\hline Year & \multicolumn{2}{l}{ Nigeria (SSCE) } & \multicolumn{2}{l}{ UK (GCE A LEVELS) } & \multicolumn{2}{c}{ Australia (HSC) } \\
\hline & $\mathbf{n}$ & $\mathbf{\%}$ & $\mathbf{n}$ & $\mathbf{\%}$ & $\mathbf{n}$ & $\mathbf{\%}$ \\
1 & 621 & 32.1 & 2838 & 65.8 & 221 & 48 \\
2 & 273 & 32.5 & 5360 & 74.3 & 818 & 51 \\
3 & 710 & 13.5 & 2160 & 83.4 & 2245 & 50 \\
4 & 1023 & 12.7 & 5086 & 79.8 & 2300 & 49.9 \\
\hline
\end{tabular}




\begin{tabular}{lllllll}
\hline 5 & 2027 & 38.3 & 7148 & 88.3 & 2500 & 53.8 \\
\hline
\end{tabular}

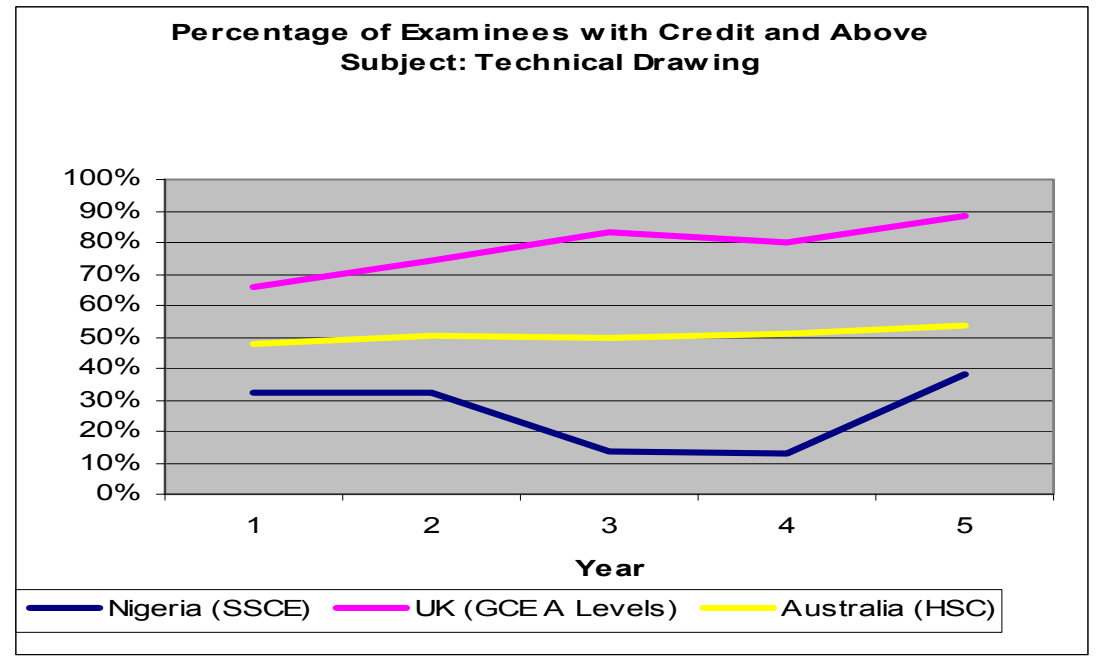

Figure 1. Percentage of examinees with credit and above in technical drawing

Table 4 shows the percentage and actual numbers of school leavers who achieved passes in art. Performance in Art has increased significantly in all three countries (Figure 2). A total of 50 percent of Australian school leavers had passes in year 1 with 58 percent achieving passes in year 5. In the UK, 69 percent of year 1 school leavers obtained passes compared to 96 percent in year 5. Only 29 percent of Nigerian school leavers had passes in year 1 which increased to 62 percent in year 5. School leavers performance in art increased significantly $F(2,12)=61.2, p<0.05$ in all three countries.

Table 4. School leavers achieving passes in Art

\begin{tabular}{lllllll}
\hline Year & \multicolumn{2}{l}{ Nigeria (SSCE) } & \multicolumn{2}{c}{ UK (GCE A LEVELS) } & \multicolumn{2}{c}{ Australia (HSC) } \\
\hline & $\mathbf{n}$ & $\mathbf{\%}$ & $\mathbf{n}$ & $\mathbf{\%}$ & $\mathbf{n}$ & $\mathbf{\%}$ \\
1 & 3255 & 29.4 & 15493 & 69.4 & 1760 & 49.5 \\
2 & 3726 & 22.1 & 14710 & 82.9 & 2140 & 50.4 \\
3 & 1164 & 53 & 21000 & 90 & 5360 & 61.6 \\
4 & 2331 & 22.2 & 31450 & 90.5 & 5925 & 63.3 \\
5 & 1089 & 62.2 & 36424 & 95.5 & 5710 & 58 \\
\hline
\end{tabular}

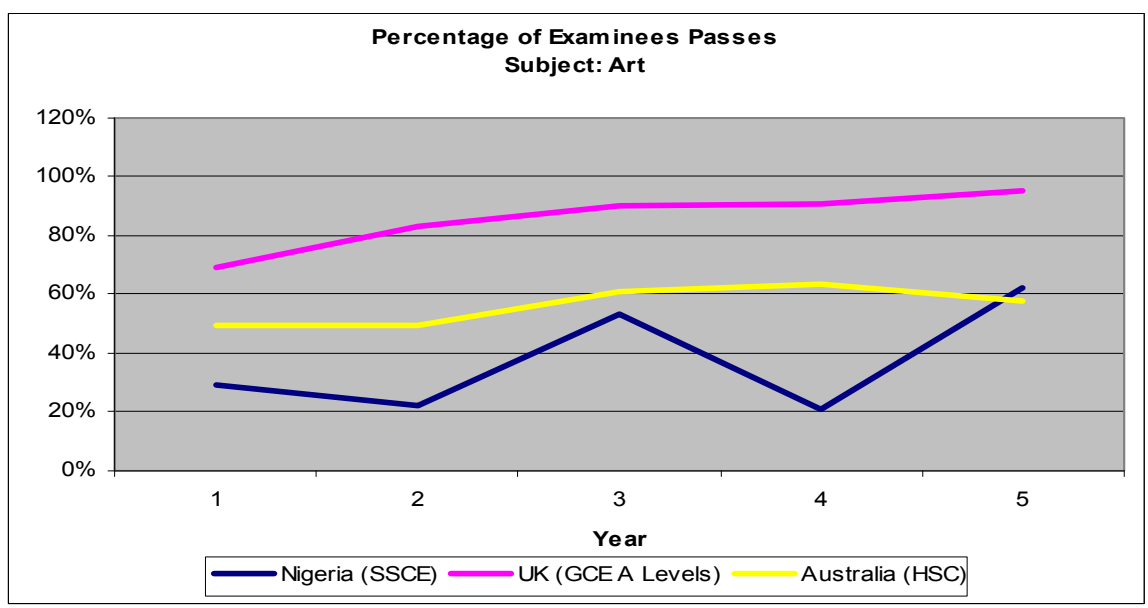


Figure 2. Percentage of examinees passes in Art

Table 5 shows the percentage and actual numbers of school leavers who achieved passes in mathematics. Performance in all three countries were statistically significant $F(2,12)=28.1, p<0.05$. Performance increased significantly in Australia from 49 percent in year 1 to 64 percent in year 5. In the UK 69 percent of the year 1 school leavers passes with a significant rise in year 5 to 90 percent. Nigeria was the only country where performance remained at 18 percent for both year 1 and year 5 school leavers. There was also a drop to 9 percent in year 3 . This rose slightly to 11 percent in year 4. This drop in performance levels may be as a result of the transition between 1989 and 1992 in the Nigerian secondary school system from a five and seven year system, to a six year system.

Table 5. School leavers achieving passes in mathematics

\begin{tabular}{lllllll}
\hline Year & \multicolumn{2}{l}{ Nigeria (SSCE) } & \multicolumn{2}{c}{ UK (GCE A LEVELS) } & \multicolumn{2}{c}{ Australia (HSC) } \\
\hline & $\mathbf{n}$ & $\mathbf{\%}$ & $\mathbf{n}$ & $\mathbf{\%}$ & $\mathbf{n}$ & $\mathbf{\%}$ \\
1 & 16117 & 18.1 & 37570 & 68.8 & 1115 & 48.6 \\
2 & 26042 & 18.1 & 41380 & 75.7 & 7521 & 49.1 \\
3 & 7985 & 8.8 & 36910 & 77.9 & 20098 & 65.9 \\
4 & 53559 & 11 & 54664 & 82.4 & 19778 & 64 \\
5 & 138098 & 18.3 & 61515 & 89.8 & 14688 & 64 \\
\hline
\end{tabular}

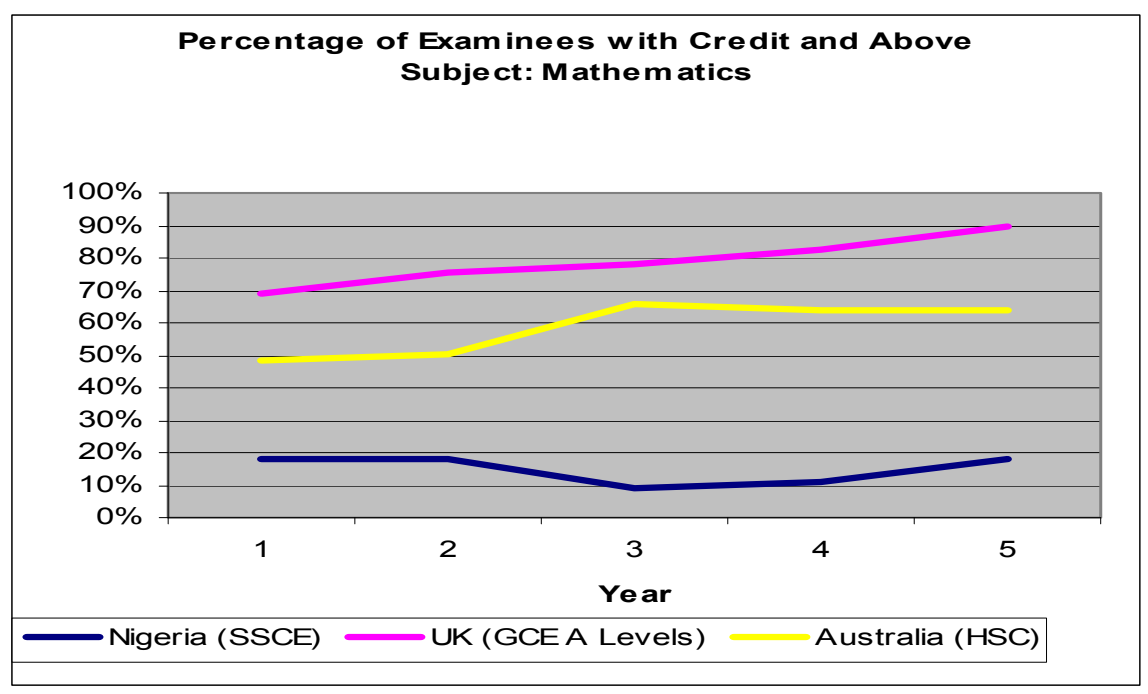

Figure 3. Percentage of examinees with credit and above in mathematics

\section{Conclusion}

Results indicate that school leavers' performance on subjects which require high levels of visuospatial ability has risen significantly. It is evident that industrialised nations such as Australia and the United Kingdom show particularly high performance levels in these subjects. This may be linked to the highly technological environment of industrialised nations. Nigeria also showed increases in school leavers' performance which suggests that developing nations may indeed be experiencing increasing visuospatial ability. This may occur regardless of how minimal access to technology and visual stimulation may be. Increasing visuospatial ability is evident in all three nations along with the reported rise in average general intelligence.

The Nigeria data however showed a slump in performance between year 3 and year 4 . As mentioned previously, and at this point, the most likely explanation is that the dip may be as a result of the transition to the 6-3-3-4 school system in 1989. This change was gradual with schools in all 32 states in Nigeria shifting from the old system to the new system very slowly. This may have affected the number of students who sat for the Senior Secondary School 
Certificate Examination between 1989 and 1993. This in turn may have had an influence on the number of passes reported by the West African Examination Council during the same period. The performance of school leavers subsequently rose in later years.

As with most research there are clear limitations to the study. Although the researcher has attempted to compare like for like subjects one must be mindful that very educational system goes through periods of change. For instance, in New South Wales Australia there has been a revamp of the curriculum authority and NSW Board of Studies structure. Whether these changes may impact on curriculum delivery is yet to be tested.

Another limitation to the current study is that testing on a sample of students using computer application or 3D video game did not occur here. Further studies may explore recruitment of such a sample.

Overall it is evident that performance in all three subject shows increases in those subjects that require visuospatial skills. It appears that these increases are occurring at different rates hence I mentioned previously may be due to a variety of factors such as internal changes within individual education bodies. In addition, using mature samples in all three countries is quite consistent with Flynn's (1987) study where raw scores of army recruits on IQ tests were analysed. Flynn pointed out that mature individuals are nearer the peak of their raw score performance when compared to children. The maturity of the school leavers have assisted in presenting accurate evidence that visuospatial abilities are increasing.

\section{Acknowledgements}

Thank you to the staff of the West African Examination Council (WAEC) for providing relevant school leavers' examination results for Nigeria. I acknowledge the assistance of Dr. Bob McCann at the former New South Wales Board of Studies (BoS) for giving me access to school leavers' examination results. Similarly, I appreciate the help of staff of the Department of Education and Skills (DfES) for providing access to UK school leavers' results and relevant longitudinal data.

\section{References}

Alias, M., Black, T. R., \& Gray, D. E. (2002) Instructions on spatial skills and spatial visualisation ability in engineering students. International Education Journal, 3(1), 1-12.

Ceci, S. J. (1991). How much does schooling influence general intelligence and it's cognitive components? A reassessment of the evidence. Developmental Psychology, 27, 703-722. http://dx.doi.org/10.1037/ 0012-1649.27.5.703

Cocodia, E. A. et al. (2003). Evidence that rising population intelligence is impacting in formal education. Personality and Individual Differences, 35(4), 797-810. http://dx.doi.org/10.1016/S0191-8869(02)00284-2

Curtis, D., \& Lawson, M. (2002). Computer adventure games as problem-solving environments. International Education Journal, 3(4), 43-56.

Flynn, J. R. (1984). The mean IQ of Americans: Massive gains 1932 to 1978. Psychology Bulletin, 95, 29-51. http://dx.doi.org/10.1037/0033-2909.95.1.29

Flynn, J. R. (1987). Massive IQ gains in 14 nations: What IQ tests really measure. Psychology Bulletin, 101, 171-191. http://dx.doi.org/10.1037/0033-2909.101.2.171

Gilhooly, K. J. (1994). Knowledge. In R. J. Sternberg (Ed.), Encyclopaedia of Human Intelligence (pp. 636-638). New York: Macmillan.

Greenfield, P. M. (1998). The cultural elevation of IQ (pp. 81-123). In U. Neisser (Ed.), The rising curve (pp. 25-66). Washington, DC: American Psychological Association.

Halpern, D. F., \& LaMay, M. L. (2000). The smarter sex: A critical review of sex differences in intelligence. Educational Psychology Review, 12(2), 229-246. http://dx.doi.org/10.1023/A:1009027516424

Lohman, D. F. (2000). Complex information processing and intelligence. In R. J. Sternberg (Ed.), Handbook of intelligence (pp. 285-340). New York: Cambridge University Press. http://dx.doi.org/10.1017/ CBO9780511807947.015

McGee, M. G. (1982). Spatial abilities, development and physiological foundations. In M. Potegal (Ed.), Spatial visualisation. New York: Academic Press.

Neisser, U. (1997). Rising scores on intelligence tests. American scientist, 85, 440-447.

Neisser, U. (1998). Introduction: Rising test scores and what they mean. In The rising curve: Long-term gains in IQ and related measures. Washington, DC: American Psychological Association. http://dx.doi.org/10.1037/ 
10270-016

Ogbu, J. U. (1994). Culture and intelligence. In R. J. Sternberg (Ed.), Encyclopaedia of human intelligence (Vol. 2, pp. 328-338). New York: Macmillan.

Okagaki, L., \& Frensch, P. A. (1994). Effects of video game playing on measures of spatial performance: Gender effects in late adolescence. Journal of Applied Developmental Psychology, 15, 33-58. http://dx.doi.org/ 10.1016/0193-3973(94)90005-1

Rice, M., \& Woodsmall, L. (1988). Lessons from television: Children's word learning when viewing. Child Development, 59, 420-429. http://dx.doi.org/10.2307/1130321

Rice, M., Huston, A., Truglio, R., \& Wright, J. (1990). Words form Sesame Street: Learning Vocabulary while viewing. Developmental Psychology, 26(3), 421-428. http://dx.doi.org/10.1037/0012-1649.26.3.421

Salomon, G. (1977). Effects of encouraging Israeli mothers to co-observe Sesame Street with their five-year-olds. Child Development, 48, 1146-1151. http://dx.doi.org/10.2307/1128378

Stein, A. H., \& Friedrich, L. K. (1975). Impact of television on children and youth. Chicago: University of Chicago Press.

Sweller, J. (1999). Instructional Design. Melbourne: Vic ACER Press.

Teasdale, T. W., \& Owen, D. R. (2000). Forty-year secular trend in cognitive abilities. Intelligence, 28, 115-120. http://dx.doi.org/10.1016/S0160-2896(99)00034-3

Thomas, P. V., \& Higbee, J. L. (1999). Affective and Cognitive factors related to mathematical achievement. Journal of Developmental Education, 23, 8-16.

WAEC. (1980). West African Examinations Council Annual Report. Lagos: Megavons press.

WAEC. (1986). West African Examinations Council Annual Report. Lagos: Megavons press.

WAEC. (1990). West African Examinations Council Annual Report. Lagos: Megavons press.

WAEC. (1994). West African Examinations Council Annual Report. Lagos: Megavons press.

WAEC. (2000). West African Examinations Council Annual Report. Lagos: Megavons press.

WAEC. (1979). West African Examinations Council Annual Report. Lagos: Megavons press.

Wilson, K. M., \& Swanson, H. L. (2001). Are mathematical disabilities due to a domain-general or domain-specific working memory deficit? Journal of Learning disabilities, 34, 237-248. http://dx.doi.org/ $10.1177 / 002221940103400304$

\section{Copyrights}

Copyright for this article is retained by the author(s), with first publication rights granted to the journal.

This is an open-access article distributed under the terms and conditions of the Creative Commons Attribution license (http://creativecommons.org/licenses/by/3.0/). 